\title{
Pim1 Overexpression Prevents Apoptosis in Cardiomyocytes After Exposure to Hypoxia and Oxidative Stress via Upregulating Cell Autophagy
}

\author{
Han-hua Zhu Xian-tao Wang Yu-han Sun Wen-kai He Jia-bao Liang \\ Bing-hai Mo Lang Li \\ Department of Cardiology, The First Affiliated Hospital of Guangxi Medical University, Nanning, China
}

Key Words

$\operatorname{Pim} 1 \cdot$ Autophagy $\bullet$ Apoptosis $\bullet$ Hypoxia $\bullet$ Oxidative stress $\bullet$ Cardiomyocyte

\begin{abstract}
Background/Aims: Microvascular obstruction (MVO), an undesirable complication of percutaneous coronary intervention, is independently associated with adverse left ventricle remodeling and poor prognosis after acute myocardial infarction. Hypoxia and oxidative stress major roles in the pathophysiology of MVO. Pim1 serves an important protective role in the ischemic myocardium, but the underlying mechanisms remain poorly defined. Autophagy in early hypoxia or during moderate oxidative stress has been demonstrated to protect the myocardium. In this study, we investigated the association between the protective effect of Pim1 and autophagy after hypoxia and oxidative stress. Methods: Ventricular myocytes from neonatal rat heart (NRVMs) were isolated. NRVMs were exposed to hypoxia and $\mathrm{H}_{2} \mathrm{O}_{2}$. Rapamycin and 3-methyladenine (3-MA) were used as an activator and inhibitor of autophagy, respectively. pHBAd-Pim1 was transfected into NRVMs. We assessed cardiomyocyte apoptosis by Annexin V-FITC/PI flow cytometry. Autophagy was evaluated by mRFP-GFPLC3 adenovirus infection by confocal microscopy. Western blotting was used to quantify apoptosis or autophagy protein (caspase-3, LC3, P62, AMPK, mTOR, ATG5) concentrations. Results: Autophagy and apoptosis in NRVMs significantly increased and peaked at $3 \mathrm{~h}$ and $6 \mathrm{~h}$, respectively, after exposure to hypoxia and $\mathrm{H}_{2} \mathrm{O}_{2}$. The mTOR inhibitor rapamycin induced autophagy and decreased cardiomyocyte apoptosis, but the autophagy inhibitor 3-MA decreased autophagy and increased apoptosis at $3 \mathrm{~h}$ after exposure to hypoxia and $\mathrm{H}_{2} \mathrm{O}_{2}$. Pim1 levels in NRVMs increased at $3 \mathrm{~h}$ and decreased gradually after exposure to hypoxia and $\mathrm{H}_{2} \mathrm{O}_{2}$. Pim1 overexpression enhanced autophagy and decreased apoptosis. Pim1-induced promotion of autophagy is partly the result of activation of the AMPK/mTOR/ATG5 pathway
\end{abstract}




\section{Cellular Physiology Cell Physiol Biochem 2018;49:2138-2150

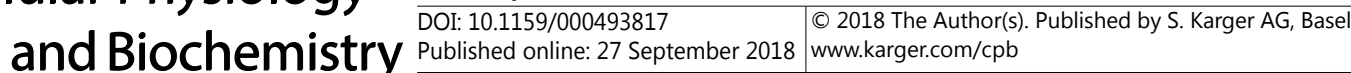 \\ Zhu et al.: Pim1 Prevents Cardiomyocytes Apoptosis via Upregulating Autophagy}

after exposure to hypoxia and $\mathrm{H}_{2} \mathrm{O}_{2}$. Conclusion: Our results revealed that Pim1 overexpression prevented NRVMs from apoptosis via upregulating autophagy after exposure to hypoxia and oxidative stress, partly through activation of the AMPK/mTOR/ATG5 autophagy pathway.

(C) 2018 The Author(s)

Published by S. Karger AG, Basel

\section{Introduction}

Percutaneous coronary intervention (PCI) is the preferred treatment for ST-segment elevation myocardial infarction (STEMI) [1]. However, reductions in door-to-balloon times have not further improved mortality in patients undergoing primary PCI [2]. Microvascular obstruction (MVO) is observed in 57\% of STEMI patients after primary PCI. The presence and extent of MVO are strongly associated with mortality and hospitalization for heart failure within 1 year [3]. Thus, MVO is a common problem in STEMI and represents a new and important target for therapy [4]. Ischemia/reperfusion injury and distal atherothrombotic embolization have major roles in the pathogenesis of MVO [4, 5]. Several treatment options, such as nitroprusside and adenosine, have been used with variable success [6]. However, because their effects have not been convincingly demonstrated, further investigation of the molecular mechanism of MVO is urgently needed. Coronary microembolization causes microvessel occlusion and persistent local myocardial hypoxia, at the same time, microvascular and parenchymal organ damage caused by ischemia/reperfusion is mainly due to reactive oxygen species (oxidative stress), which has been demonstrated in various organs. $\mathrm{H}_{2} \mathrm{O}_{2}$ is an important reactive oxygen free radical in the body. Therefore, we established an in vitro environment of hypoxia and $\mathrm{H}_{2} \mathrm{O}_{2}$ in cardiomyocytes to simulate the pathophysiological process of MVO.

In our previous study using a porcine model, we demonstrated that MVO involved cardiomyocyte apoptosis, and inhibition of apoptosis could improve cardiac function [7]. Autophagy is considered an essential process of self-digestion in the turnover of cytoplasmic components and is generally a protective mechanism to evade cell death via degrading damaged organelles or harmful substances. It is a catabolic process that provides nutrients during starvation [8]. Katheder et al. reported that the microenvironmental contributes to early tumor growth through nutrient-generating autophagy [9]. Autophagy preserves cardiac structure and function under baseline conditions and is activated during stress, limiting damage under most conditions. It reduces injury and preserves cardiac function during ischemia [10]. Histone deacetylase inhibition blunts ischemia/reperfusion injury by inducing cardiomyocyte autophagy [11]. It is not clear whether cardiomyocyte apoptosis can be inhibited by active autophagy under hypoxic conditions in the presence of $\mathrm{H}_{2} \mathrm{O}_{2}$.

The Pim kinases are a family of three serine/threonine kinases (Pim1, Pim2, and Pim3). The Pim kinases play pivotal roles in cell cycle regulation, apoptosis, stem cells, metabolism, drug resistance, and targeted therapy [12]. Pim1 expression is upregulated in cardiomyocytes after pressure overload or infarction, suggesting that it serves an important protective role in the heart $[13,14]$. Whether Pim 1 inhibits apoptosis by promoting autophagy is not clear in the setting of hypoxia and $\mathrm{H}_{2} \mathrm{O}_{2}$.

The purpose of this study was to explore the association between autophagy and apoptosis in ventricular myocytes from neonatal rat heart (NRVMs) after exposure to hypoxia and $\mathrm{H}_{2} \mathrm{O}_{2}$, and to determine whether and how Pim1 inhibits apoptosis through an increase in autophagy.

\section{Materials and Methods}

\section{NRVM primary culture and purity testing}

All animal procedures were approved by the Animal Care and Use Committee of Guangxi Medical University. Primary cardiomyocytes were isolated enzymatically with trypsin and collagenase II (SigmaAldrich, St. Louis, MO, USA) from 1- to 2-day-old Sprague-Dawley rat ventricles according to our previous 


\section{Cellular Physiology Cell Physiol Biochem 2018;49:2138-2150 \begin{tabular}{l|l|l}
\hline and Biochemistry 10.1159/000493817 & $\begin{array}{l}\text { @ } 2018 \text { The Author(s). Published by S. Karger AG, Basel } \\
\text { www.karger.com/cpb }\end{array}$ \\
\hline
\end{tabular}

protocol [15]. The ventricles were digested and stirred in $0.08 \%$ trypsin with $0.04 \%$ collagenase II. Then, the supernatant was transferred to a new sterile tube and centrifuged at $1200 \mathrm{rpm}$ for $3 \mathrm{~min}$. To remove the cardiac fibroblasts, the cells were seeded onto an uncoated plate at $37^{\circ} \mathrm{C}$ in a $5 \% \mathrm{CO}_{2}$ incubator. After $90 \mathrm{~min}$, the unattached cells were transferred onto plates precoated with Dulbecco's modified Eagle's medium (DMEM; Gibco, Gaithersburg, MD, USA) supplemented with 10\% fetal bovine serum (FBS; Gibco), $1 \%$ penicillin-streptomycin (Solarbio, Beijing, China), and $100 \mu \mathrm{mol} / \mathrm{L} 5-\mathrm{BrdU}$. After culturing for $36 \mathrm{~h}$, the medium was replaced with fresh medium. The cultured cardiomyocytes were used for experiments $72 \mathrm{~h}$ after initial attachment.

The cardiomyocytes were permeabilized with $0.2 \%$ Triton X-100 with subsequent washing with phosphate-buffered saline (PBS). Primary antibody incubation with sarcomeric $\alpha$-actinin (Abcam, Cambridge, MA, USA; catalog no. ab9465) was carried out at $4^{\circ} \mathrm{C}$ overnight. Sections were incubated with fluorescent secondary goat anti-mouse (Alexa Fluor 488 conjugate; Abcam; catalog no. ab150113) antibodies for $1 \mathrm{~h}$ in the dark at room temperature $\left(25^{\circ} \mathrm{C}\right)$. Nuclei were stained with $4^{\prime}, 6$-diamidino-2phenylindole (Sigma-Aldrich). Immunofluorescent images were observed under a fluorescence microscope (magnification $\times 100$, Olympus, Tokyo, Japan). The presence of sarcomeric $\alpha$-actinin in the cytoplasm of cardiomyocytes could be visualized (green fluorescence). Five different fields were counted to calculate the purity of the cardiomyocytes.

\section{NRVM hypoxia and oxidative stress}

The NRVM culture medium was replaced by low-glucose DMEM without FBS with different concentrations $(0,50,100$, and $200 \mu \mathrm{M})$ of $\mathrm{H}_{2} \mathrm{O}_{2}$ (oxidative stress condition); standard culture medium was used for the control group. Subsequently, the cells were cultured in an anoxia chamber (HERAcell VIOS 160i, Thermo Fisher Scientific Inc., Waltham, MA, USA), saturated with $92 \% \mathrm{~N}_{2}, 5 \% \mathrm{CO}_{2}$, and $3 \% \mathrm{O}_{2}(\mathrm{v} / \mathrm{v} / \mathrm{v})$ at $37^{\circ} \mathrm{C}$ for $3,6,9$, and $12 \mathrm{~h}$. The appropriate concentration of $\mathrm{H}_{2} \mathrm{O}_{2}$ was defined to cause relatively moderate injury. The appropriate hypoxia time was defined to cause obvious autophagy. For drug treatment, cells were pretreated with $200 \mathrm{nM}$ rapamycin (Sigma-Aldrich) or $10 \mathrm{mM}$ 3-methyladenine (3-MA; Sigma-Aldrich) $2 \mathrm{~h}$ before hypoxia.

\section{Cell viability assay}

The Cell Titer 96® AQueous One Solution Cell Proliferation Assay (Promega, Madison, WI, USA) containing 3-(4, 5-dimethylthiazol-2-yl)-5-(3 carboxymethoxyphenyl)-2-(4-sulfophenyl)-2H-tetrazolium (MTS) and the electron coupling reagent phenazine methosulfate was used to determine cell viability. After incubation of NRVMs for various periods, $20 \mu \mathrm{L}$ detection reagent was added to each well. Optical density was measured at $490 \mathrm{~nm}$ after $2 \mathrm{~h}$. The results were presented as a percentage relative to the control group. NRVM activity was expressed as a percentage relative to the control group.

\section{Flow cytometry assay}

Flow cytometry was performed to detect cell apoptosis using an Annexin V-FITC and propidium iodide (PI) double staining kit (BD Biosciences, Franklin Lakes, NJ, USA) according to the manufacturer's instructions. Briefly, after treatment as indicated, NRVMs were collected and then resuspended in $500 \mu \mathrm{L}$ binding buffer. Then, aliquots $(100 \mu \mathrm{L})$ of the solution were transferred for incubation with $5 \mu \mathrm{L}$ FITCAnnexin $\mathrm{V}$ and $5 \mu \mathrm{L}$ PI, followed by gently vortexing for $15 \mathrm{~min}$ at room temperature in the dark. Samples were analyzed using a flow cytometer within $1 \mathrm{~h}$ (FACSCalibur, BD Biosciences).

\section{Western blot analysis}

Protein was extracted from the NRVMs by adding cell lysis buffer (Sigma-Aldrich). Equivalent proteins $(20 \mu \mathrm{g})$ were separated by sodium dodecyl sulfate-polyacrylamide gels $(10-15 \%)$ and electrically transferred to polyvinylidene difluoride membranes (Merck Millipore, Burlington, MA, USA). The membranes were probed with the following rabbit primary antibodies in buffer (1:500-1000 dilution) overnight at $4{ }^{\circ} \mathrm{C}$ : antiLC3B, anti- P62, anti-phospho-mTOR, anti-mTOR, anti-ATG5, anti-phospho-AMPK, anti-AMPK, anti-Parkin (Cell Signaling Technology, Danvers, MA, USA), anti- caspase-3, anti-Pim1, and anti- $\beta$-actin (Abcam). After 


\section{Cellular Physiology Cell Physiol Biochem 2018;49:2138-2150

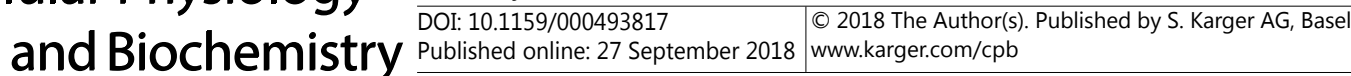 \\ Zhu et al.: Pim1 Prevents Cardiomyocytes Apoptosis via Upregulating Autophagy}

washing three times in tris-buffered saline with Tween 20, the membranes were incubated with fluorescent anti-rabbit secondary antibody (Abcam) in buffer (1:10, 000 dilution) at room temperature for $2 \mathrm{~h}$. The immunoreactive bands were observed by exposing the blots in an Odyssey infrared imaging system (LI-COR Biosciences, Lincoln, NE, USA). Densitometric analysis was performed using ImageJ software. Three to five independent experiments were performed, and the average densitometry values were calculated.

mRFP-GFP-LC3 and $p H B A d-P i m 1$ adenovirus infection

mRFP-GFP-LC3, pHBAd-Pim1, and pHBAd-GFP adenoviral vectors were purchased from HanBio Technology Co., Ltd. (Shanghai, China). NRVMs were plated onto slides in 24-well plates and allowed to reach $50-70 \%$ confluence at the time of transfection. The pHBAd-GFP adenovirus was used as a control. Adenoviral infection was performed according to the manufacturer's instructions. NRVMs were incubated in growth medium with the adenoviruses at a multiplicity of infection of 100 for $2 \mathrm{~h}$ at $37^{\circ} \mathrm{C}$, and were then grown in new medium for another $36 \mathrm{~h}$ at $37^{\circ} \mathrm{C}$. After infection, NRVMs were treated with hypoxia and $\mathrm{H}_{2} \mathrm{O}_{2}$ for subsequent experiments. Autophagy was detected using a confocal scanning laser microscope (NIKON, Tokyo, Japan). Autophagic flux was evaluated as the number of GFP, RFP, and merged points (point/cell).

\section{Transmission electron microscopy (TEM)}

NRVMs were grown on 6-well plates to $80 \%$ confluency. After experiments, cells were washed with PBS and immediately fixed in $2.5 \%$ glutaraldehyde in $0.1 \mathrm{M}$ sodium cacodylate buffer followed by postfixation with $1 \%$ osmium tetroxide for $1 \mathrm{~h}$ at room temperature. The specimens were then dehydrated with ascending concentrations of ethanol (50-100\%) and embedded in Spurr's epoxy resin. Then, thin sections (60-80 nm) were cut with an ultramicrotome and mounted on copper mesh grids. The sections were then stained with $1 \%$ uranyl acetate and lead citrate, and examined by TEM (H-7650, Hitachi, Tokyo, Japan).

\section{Quantitative reverse transcription PCR (RT-PCR)}

To assess the mRNA expression levels of Pim1 in NRVMs, RNA was extracted using Trizol Reagent (Takara Bio, Kusatsu, Japan) according to the manufacturer's protocol. The concentration of RNA was quantified using NanoDrop (Thermo Fisher Scientific Inc.). Complementary DNA was synthesized using the TaqMan Reverse Transcription Kit (Takara). Quantitative RT-PCR was then performed using Power SYBR Green Master Mix (Applied Biosystems, Foster City, CA, USA) on an ABI PRISM 7500 system (Applied BioSystems). The sequences of the Pim 1 were as follows: Pim1 forward: $5^{\prime}$ - TGCTCTTGTCCAAGATCAACTC- $3^{\prime}$ and reverse: $5^{\prime}$ - CAGGGGCTCCTTCTCTTTGC-3'; $\beta$-actin forward: $5^{\prime}$-GAGATTACTGCCCTGGCTCCTA- $3^{\prime}$ and reverse: $5^{\prime}$-CATCGTACTCCTGCTTGCTGAT- ${ }^{\prime}$. We calculated the relative level of Pim1 mRNA expression using the $2^{-\Delta \Delta \mathrm{Ct}}$ method, normalized relative to $\beta$-actin.

\section{Statistical analysis}

Statistical analysis was performed using the software GraphPad Prism 6.0 (GraphPad Software, La Jolla, CA, USA). Student's unpaired t-test was used to analyze the difference between two groups, and a one-way analysis of variance with Bonferroni correction was used for multiple comparisons. $\mathrm{P}<0.05$ was considered statistically significant. All experiments were performed at least three times.

\section{Results}

\section{NRVM purity}

The purity of cultured cardiomyocytes was determined by immunofluorescence staining after 3 days in culture (Fig. 1A). The purity of cardiomyocytes was found to be $97.86 \pm 1.22 \%$.

\section{NRVM viability assay at different $\mathrm{H}_{2} \mathrm{O}_{2}$ concentrations in a hypoxic environment}

The viability of NRVMs treated with increasing concentrations of $\mathrm{H}_{2} \mathrm{O}_{2}$ in a hypoxic environment, as determined by the MTS assay at different time points, decreased in a doseand time-dependent manner (Fig. 1B). The viability of NRVMs in the $100 \mu \mathrm{M} \mathrm{H}_{2} \mathrm{O}_{2}$ group decreased by about $50 \%$ at $12 \mathrm{~h}$ after hypoxia. Thus, we chose $100 \mu \mathrm{M}$ as the appropriate $\mathrm{H}_{2} \mathrm{O}_{2}$ concentration to simulate in vitro oxidative stress. 
Fig. 1. Determination of NRVM purity and viability at different $\mathrm{H}_{2} \mathrm{O}_{2}$ concentrations in a hypoxic environment. (A) Both the cytoplasm ( $\alpha$-actinin; green) and nucleus (blue) are stained in cardiomyocytes. Only nucleus (blue) stained cell are noncardiomyocytes. Magnification 100×. (B) Viability of NRVMs treated with increasing concentrations of $\mathrm{H}_{2} \mathrm{O}_{2}$ and hypoxia, as determined by the MTS assay at different time points, decreased in a dose- and time-dependent manner.
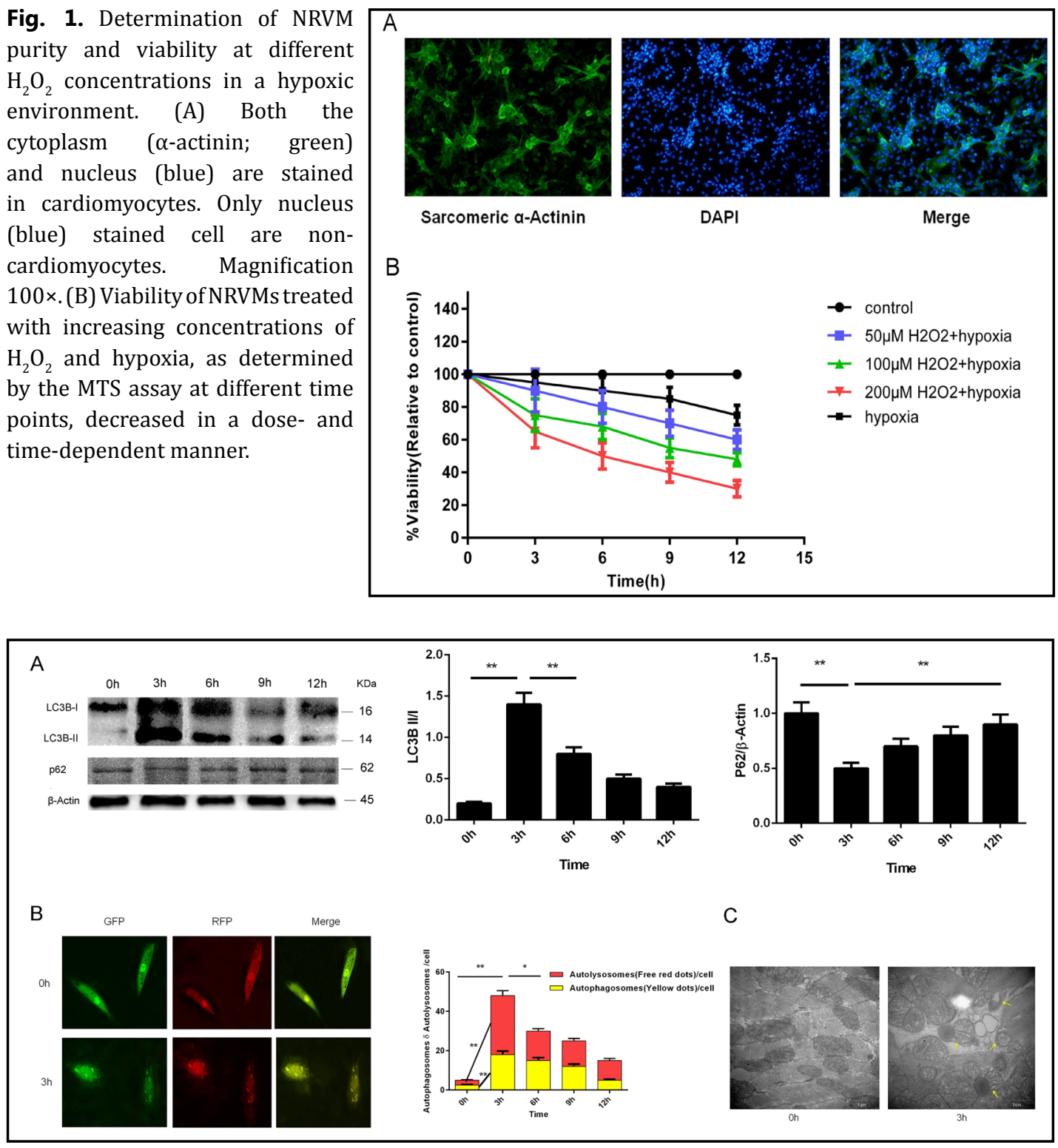

Fig. 2. NRVM autophagy significantly increased after exposure to hypoxia and $100 \mu \mathrm{M} \mathrm{H}_{2} \mathrm{O}_{2}$. (A) Western blot analysis revealed changes in LC3BI, LC3BII and P62 at different time points. (B) Fluorescence microscopy analysis of NRVMs, infected with adenovirus mRFP-GFP-LC3, $3 \mathrm{~h}$ after exposure to hypoxia and $100 \mu \mathrm{M}$ $\mathrm{H}_{2} \mathrm{O}_{2}$. Autophagy and autophagic flux increased significantly at a peak of $3 \mathrm{~h}$, and then gradually decreased, but remained higher than at $0 \mathrm{~h}$. Magnification 200×. (C) Autophagy was evaluated using TEM, with yellow arrows indicating the presence of autophagolysosomes or autophagosomes. Magnification 30,000×. ${ }^{\mathrm{P}}<0.05$ and ${ }^{* *} \mathrm{P}<0.01$. All results are the mean $\pm \mathrm{SEM}$ of three independent experiments.

NRVM autophagy significantly increased after exposure to hypoxia and $100 \mu \mathrm{M} \mathrm{H}_{2} \mathrm{O}_{2}$

We detected autophagy through monitoring the proportion of LC3BI conversion to LC3BII and the levels of P62, which are the two pivotal protein markers for phagophore and autophagosome formation. As shown in Fig. 2A, LC3BII/LC3BI was increased significantly at the peak time of $3 \mathrm{~h}$, and then gradually decreased but remained higher than at $0 \mathrm{~h}$. Meanwhile, P62 expression was decreased at the end of $3 \mathrm{~h}$. Increased autophagosomes or interruption of the autophagosome-lysosome fusion process may result in an accumulation of LC3BII, so autophagic flux was monitored with tandem fluorescent-tagged LC3 (mRFP- 
EGFP-LC3). In merged images, yellow (green and red) represented autophagosomes and red represented autolysosomes. Our autophagic flux results showed that the numbers of autophagosomes (mRFP + EGFP + dots) and particularly autolysosomes (mRFP + dots) increased within the initial $3 \mathrm{~h}$ of hypoxia, then gradually decreased, but remained than at 0 $\mathrm{h}$ (Fig. 2B). TEM results showed that NRVM autophagosomes, autolysosomes, and lysosomes significantly increased, with marked mitophagy, after exposure to hypoxia and $100 \mu \mathrm{M}$ $\mathrm{H}_{2} \mathrm{O}_{2}$ at $3 \mathrm{~h}$ compared with $0 \mathrm{~h}$ (Fig. 2C). Overall, these data suggest that NRVM autophagy significantly increased after exposure to hypoxia and $100 \mu \mathrm{M} \mathrm{H}_{2} \mathrm{O}_{2}$ at the peak time of $3 \mathrm{~h}$, and then gradually decreased but remained higher than at $0 \mathrm{~h}$.

NRVM apoptosis significantly increased after exposure to hypoxia and $100 \mu^{M H_{2} \mathrm{O}_{2}}$

After exposure to hypoxia and $100 \mu \mathrm{M} \mathrm{H}_{2} \mathrm{O}_{2}$, cleaved caspase-3/caspase- 3 western blotting results showed that activation of caspase- 3 increased significantly within $3 \mathrm{~h}$, reached a peak at $6 \mathrm{~h}$, and then decreased gradually but remained higher than at $0 \mathrm{~h}$. Flow cytometry results were similar. Moreover, NRVM apoptosis at $6 \mathrm{~h}$ was significantly greater than necrosis $(28.9 \pm 2.5 \%$ vs $6.2 \pm 0.71 \%$, $\mathrm{P}<0.01)$, indicating that apoptosis is the main cause of early myocardial cell loss after exposure to hypoxia and $100 \mu \mathrm{M} \mathrm{H}_{2} \mathrm{O}_{2}$ (Fig. 3A, B). Our previou study [7] showed that inhibition of myocardial apoptosis can improve cardiac function early after coronary artery embolization. NRVM apoptosis increased significantly after hypoxia and $\mathrm{H}_{2} \mathrm{O}_{2}$ treatment for $3 \mathrm{~h}$, so we chose $3 \mathrm{~h}$ for the time point to measure apoptosis in the following experiments.

\section{Effects of rapamycin and 3-MA on autophagy and apoptosis}

To clarify the relationship between autophagy and apoptosis, we treated cardiomyocytes with $200 \mathrm{nM}$ rapamycin or $10 \mathrm{mM}$ 3-MA for $2 \mathrm{~h}$ before hypoxia and $\mathrm{H}_{2} \mathrm{O}_{2}$. NRVMs were harvested at $3 \mathrm{~h}$ after exposure to hypoxia and $\mathrm{H}_{2} \mathrm{O}_{2}$. Rapamycin increased the ratio of LC3BII/I, and reduced the content of P62 and the ratio of cleaved caspase-3/caspase-3. This indicates that rapamycin promoted autophagy and inhibited apoptosis at $3 \mathrm{~h}$ after hypoxia and $\mathrm{H}_{2} \mathrm{O}_{2}$. However, 3-MA inhibited autophagy and promoted apoptosis (Fig. 4).

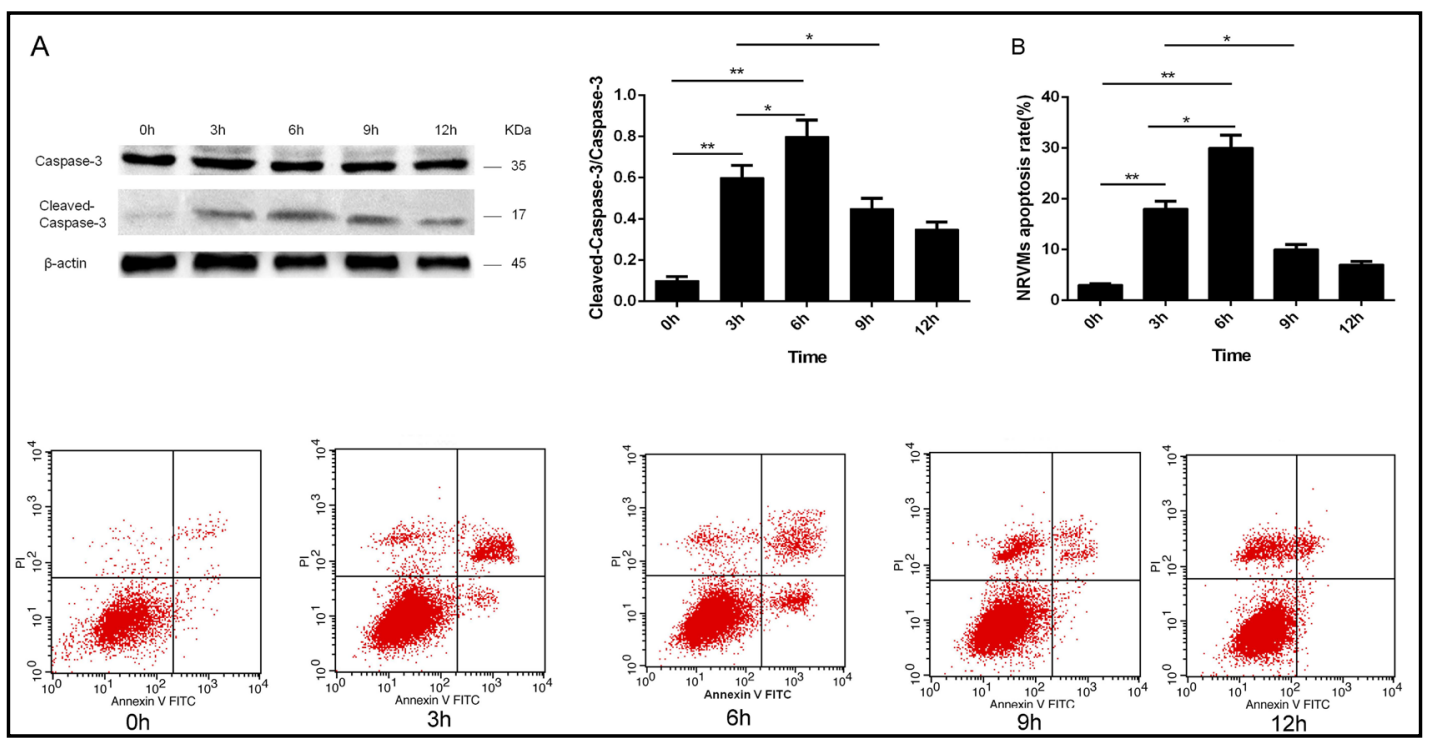

Fig. 3. NRVM apoptosis significantly increased after exposure to hypoxia and $100 \mu \mathrm{M} \mathrm{H}_{2} \mathrm{O}_{2}$. (A) Western blot analysis showed caspase- 3 and cleaved caspase- 3 content at different time points. The ratio of cleaved caspase-3/caspase-3 represents the relative activation level of caspase-3. (B) Annexin VFITC/PI staining by flow cytometry showed that the NRVM apoptosis rate was $18 \%$ at $3 \mathrm{~h}$ and increased by $30 \%$ at $6 \mathrm{~h}$, which was significantly higher than at $0 \mathrm{~h}$. ${ }^{*} \mathrm{P}<0.05$ and ${ }^{* *} \mathrm{P}<0.01$. All results are the mean \pm SEM of three independent experiments. 


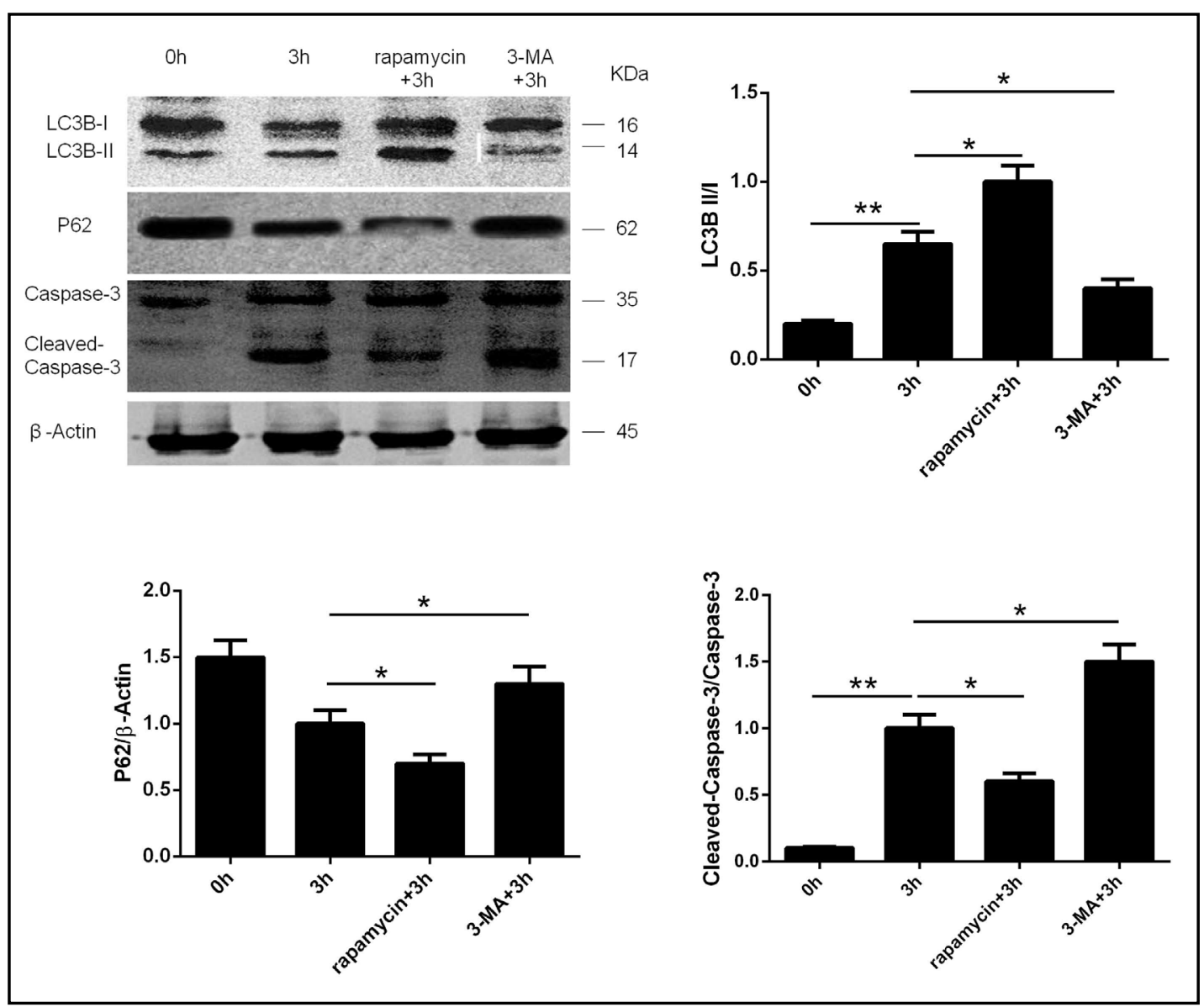

Fig. 4. Effects of rapamycin and 3-MA on autophagy and apoptosis.Rapamycin promoted autophagy and inhibited apoptosis. However, 3-MA inhibited autophagy and promoted apoptosis at $3 \mathrm{~h}$ after exposure to hypoxia and $\mathrm{H}_{2} \mathrm{O}_{2} \cdot{ }^{*} \mathrm{P}<0.05$ and ${ }^{* *} \mathrm{P}<0.01$. All results are the mean $\pm \mathrm{SEM}$ of three independent experiments.

Pim1 overexpression enhanced autophagy and decreased apoptosis at 3 h after hypoxia and $\mathrm{H}_{2} \mathrm{O}_{2}$

Pim1 expression increased rapidly by 2.5 -fold at $3 \mathrm{~h}$ compared with $0 \mathrm{~h}$ after hypoxia and $\mathrm{H}_{2} \mathrm{O}_{2}$, reaching a peak, and then gradually decreasing from $6 \mathrm{~h}$, but remained higher than at 0 h (Fig. 5A). Western blot results confirmed that Pim1 expression in the pHBAdPim1 $+3 \mathrm{~h}$ group increased 1.2-fold compared with the blank virus group (pHBAd-GFP+ $3 \mathrm{~h}$ group) and the virus-free transfection group ( $3 \mathrm{~h}$ group), and RT-PCR confirmed that Pim1 mRNA content increased 3.1-fold. These results suggest successful adenovirus transfection was as shown byPim1 overexpression (Fig. 5B). Pim1 overexpression markedly increased NRVM autophagy at $3 \mathrm{~h}$ after hypoxia and $\mathrm{H}_{2} \mathrm{O}_{2}$, as evidenced by significantly increased ratio of LC3BII/I and decreased P62 content. In addition, increased autophagosomes and autolysosomes, particularly the latter autophagic flux, confirmed these results (Fig. 6A, B). Pim1 overexpression markedly decreased NRVM apoptosis at $3 \mathrm{~h}$ after hypoxia and $\mathrm{H}_{2} \mathrm{O}_{2}$ as demonstrated by western blot, which showed a decreased cleaved caspase-3/caspase- 3 ratio compared with the control (Fig. 6A, B). Flow cytometry results were similar. NRVM apoptosis in the pHBAd $+3 \mathrm{~h}$ group significantly decreased compared with the $3 \mathrm{~h}$ group $(18.2 \pm 1.7 \%$ vs $12.1 \pm 0.88 \%, \mathrm{P}<0.05)$, and there was a decreasing trend toward NRVM necrosis, but the results were not statistically significant $(4.8 \pm 0.5 \%$ vs $3.5 \pm 0.4 \%, P>0.05$ ) (Fig. 6C). 
Fig. 5. Pim1 expression with time after hypoxia and $\mathrm{H}_{2} \mathrm{O}_{2}$. (A) Dynamic changes of Pim1 expression with time after hypoxia and $\mathrm{H}_{2} \mathrm{O}_{2}$. (B) Quantification of Pim-1 protein expression using western blotting and Pim1 mRNA using quantitative RT-PCR at $3 \mathrm{~h}$ after exposure to hypoxia and $\mathrm{H}_{2} \mathrm{O}_{2}$. $* \mathrm{P}<0.05$ and ${ }^{*} \mathrm{P}<$ 0.01. All results are the mean \pm SEM of three independent experiments.

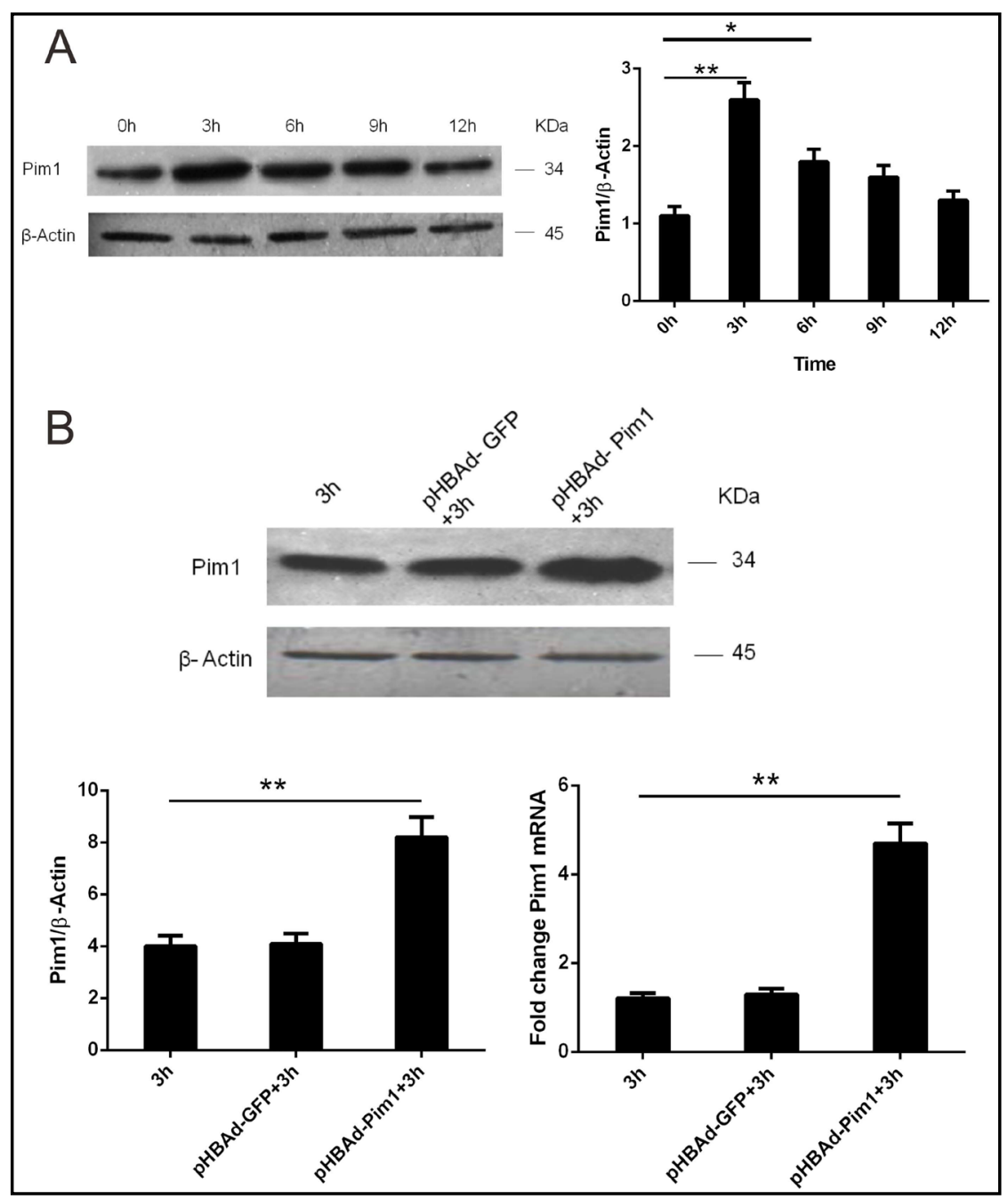

Pim1 promotes autophagy partly via the AMPK/mTOR/ATG5 pathway and promotes Parkin expression after hypoxia and $\mathrm{H}_{2} \mathrm{O}_{2}$

Our results showed that the ratio of p-AMPK/AMPK and ATG5 expression were significantly higher in the pHBAd-Pim $1+3 \mathrm{~h}$ group than in the $3 \mathrm{~h}$ group. However, the ratio of p-mTOR/mTOR expression levels was significantly lower in the pHBAd-Pim $1+3 \mathrm{~h}$ group than in the $3 \mathrm{~h}$ group. Therefore, the above results indicated that Pim 1 promotes autophagy at least partly mediated by the AMPK/mTOR/ATG5 pathway after hypoxia and $\mathrm{H}_{2} \mathrm{O}_{2}$ (Fig. 7). Parkin is one of the most important markers of mitophagy. In myocytes, loss of Parkin causes accumulation of abnormal mitochondria and cell death [16-19]. Our western blot results showed that Pim1 overexpression markedly increased the expression of Parkin, indicating that Pim1 overexpression increased mitophagy in NRVMs after hypoxia and $\mathrm{H}_{2} \mathrm{O}_{2}$ (Fig. 7).

\section{Discussion}

In this study, we found that Pim1 overexpression promoted cardiomyocyte autophagy and inhibited apoptosis in the presence of hypoxia and $\mathrm{H}_{2} \mathrm{O}_{2}$, partly through activation of the AMPK/mTOR/ATG5 pathway. MVO is a common and important complication of acute myocardial infarction after PCI and is an important predictor of long-term mortality [20]. Ischemia/reperfusion injury and distal atherothrombotic embolization are two major pathological processes responsible for the occurrence of MVO. Persistent hypoxia and 


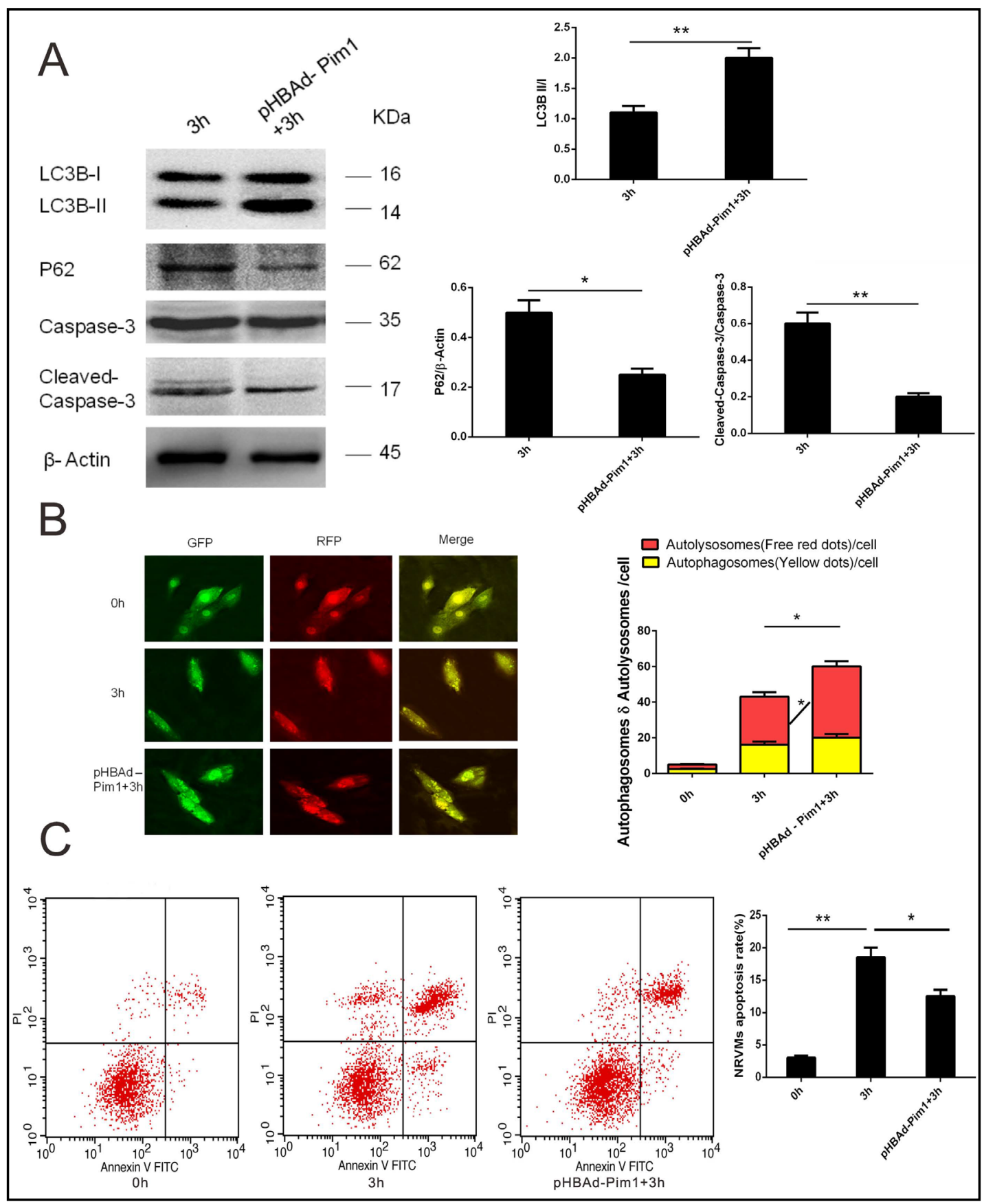

Fig. 6. Pim 1 overexpression enhanced autophagy and decreased apoptosis at $3 \mathrm{~h}$ after hypoxia and $\mathrm{H}_{2} \mathrm{O}_{2}$. (A) Pim1 overexpression increased the ratio of LC3BII/I, reduced the content of P62, and reduced the ratio of cleaved caspase-3/caspase-3. (B) Autophagy and autophagy flux increased significantly at $3 \mathrm{~h}$ after hypoxia and $\mathrm{H}_{2} \mathrm{O}_{2}$. Magnification 200×. (C) Pim1 overexpression decreased apoptosis as demonstrated by flow cytometry. ${ }^{*} \mathrm{P}<0.05$ and ${ }^{* *} \mathrm{P}<0.01$. All results are the mean $\pm \mathrm{SEM}$ of three independent experiments.

oxidative stress are important pathophysiological mechanisms of MVO [5]. In the presence of hypoxia and $\mathrm{H}_{2} \mathrm{O}_{2}$, neonatal cardiomyocytes first demonstrated a peak in autophagy, then apoptosis peaked, followed by a gradual decrease in cardiomyocyte viability and an increase in myocardial necrosis. This pathological process is consistent with the findings from our previously reported rat model of coronary microembolism [21, 22].

Cardiomyocyte autophagy contributes to maintain homeostasis under different 


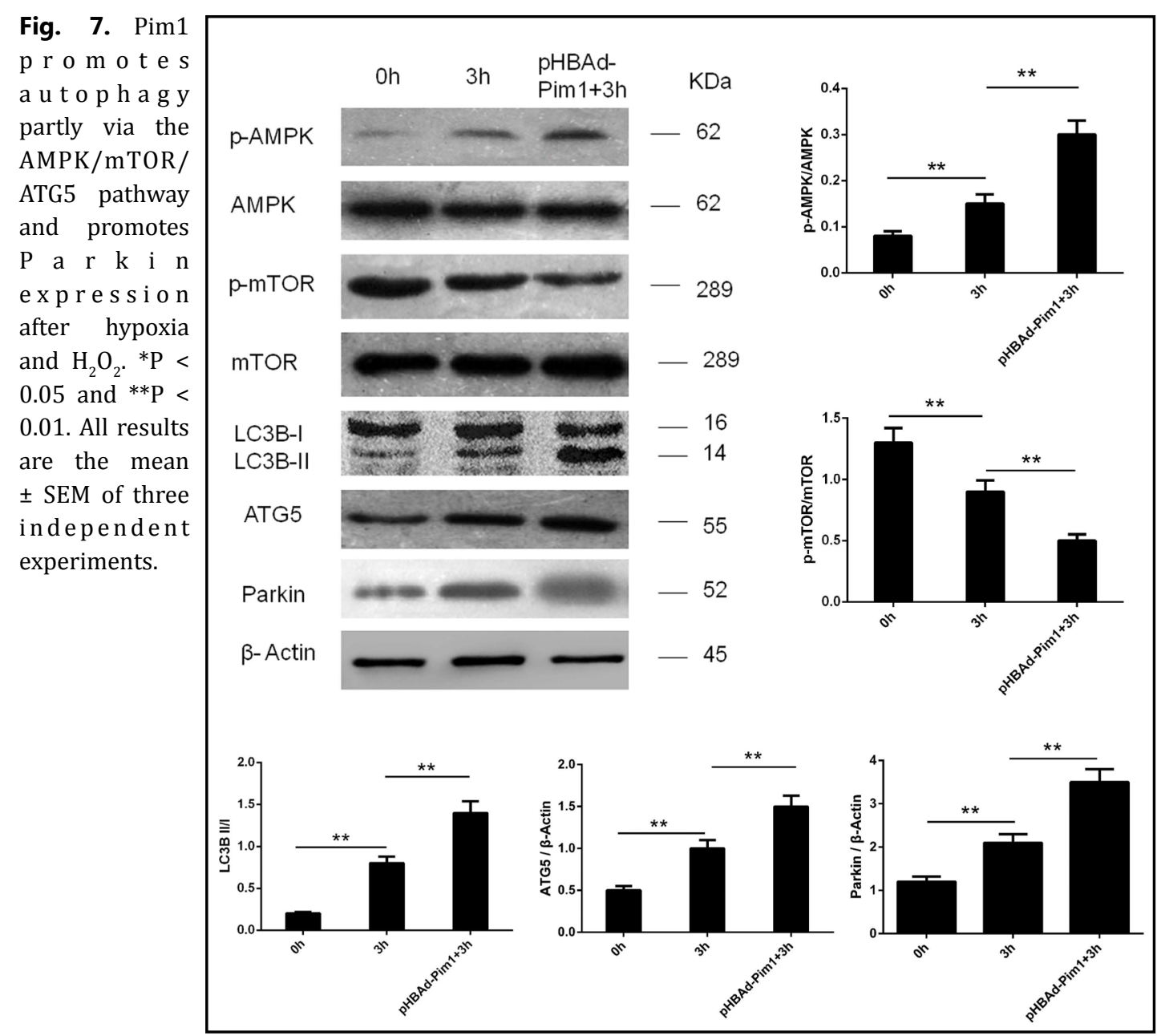

circumstances. Moreover, pharmacological or genetic therapies that affect cardiomyocyte autophagy or autophagic flux in different animal models of myocardial infarction can alter prognosis. Most studies suggest that autophagy limits, rather than exacerbates, myocardial damage on infarction [23]. Interestingly, there is no consensus regarding whether autophagic flux is increased or impaired during cardiomyocyte reperfusion $[24,25]$. However, recently, increasingly more evidence supports the notion that an increase in autophagy during ischemia/reperfusion is protective [26-29]. Min et al. found that suberoylanilide hydroxamic acid (SAHA, a histone deacetylase inhibitor) reduced myocardial infarct size in a rabbit model by inducing cardiomyocyte autophagy, specifically in the border zone of ischemia/ reperfusion injured hearts. Additionally, in an ischemia/reperfusion in vitro model, increased autophagy was required for protection by SAHA against cell death [11]. We also found that rapamycin promoted cardiomyocyte autophagy and inhibited apoptosis following hypoxia and $\mathrm{H}_{2} \mathrm{O}_{2}$, whereas 3-MA inhibited autophagy but increased NRVM apoptosis. Pim1 overexpression enhanced autophagy and decreased apoptosis following hypoxia and $\mathrm{H}_{2} \mathrm{O}_{2}$, and in particular autophagic flux was increased.

Overexpression of Pim1 is associated with enhanced cell survival, elongation of telomeres [30], enhanced metabolic activity [31], attenuation of cell apoptosis, and preservation of mitochondrial integrity [32]. However, there have been few studies of the effects of Pim kinases on autophagy. Bohensky et al. found that Pim2 promoted expression of LC3B and Beclin-1 and enhanced lysosomal acidification [33]. Jingang et al. reported that Pim-3 knockdown in NPC HNE-1 cells enhanced apoptosis, decreased cell proliferation, and inhibited autophagy and invasion in the presence or absence of docetaxel [34]. Hao et 


\section{Cellular Physiology Cell Physiol Biochem 2018;49:2138-2150

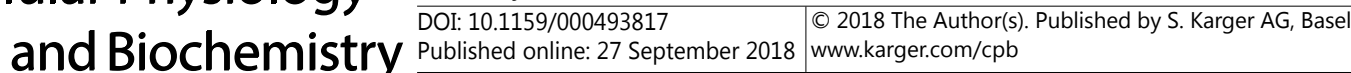 \\ Zhu et al.: Pim1 Prevents Cardiomyocytes Apoptosis via Upregulating Autophagy}

al. reported that knockdown of Pim1 significantly attenuated hypoxia-induced autophagy, whereas Pim 1 overexpression markedly enhanced hypoxia-induced autophagy in prostate cancer cells [35]. We found that Pim1 overexpression enhanced autophagy and decreased apoptosis in vitro in NRVMs in the presence of hypoxia and $\mathrm{H}_{2} \mathrm{O}_{2}$.

The relationship between autophagy and apoptosis is highly context dependent. Cardiomyocytes are rich in mitochondria. In the presence of hypoxia or oxidative stress, mitochondrial membrane permeability is impaired, inducing the release of cytochrome $\mathrm{C}$ and inducing cardiomyocyte apoptosis. Mitophagy can remove the damaged mitochondria, thus increasing the threshold for apoptosis induction [36, 37]. We found that cardiomyocyte autophagy peaked before apoptosis in the presence of hypoxia and $\mathrm{H}_{2} \mathrm{O}_{2}$. Previous investigations have suggested that mTOR is inhibited during energy insufficiency, which subsequently stimulates autophagy. During myocardial ischemia or R/I ischemia/ reperfusion injury in vivo and in vitro, the AMPK/mTOR pathway is activated $[38,39]$. Our results revealed that Pim1 upregulated autophagy after hypoxia and $\mathrm{H}_{2} \mathrm{O}_{2}$, partly because of activation of the AMPK/mTOR/ATG5 autophagy pathway.

There are several potential limitations that should be considered. First, these results were derived from neonatal rat cardiomyocytes, which may not be equivalent to adult rat cardiomyocytes. Second, in vitro simulation of MVO is not the same as MVO after PCI in acute myocardial infarction in vivo. Therefore, future studies in adult cardiomyocytes and in the in vivo setting are required.

\section{Conclusion}

Our results revealed that Pim1 overexpression prevented NRVM apoptosis via upregulation of autophagy after hypoxia and oxidative stress, partly via activation of the AMPK/mTOR/ATG5 autophagy pathway. Pim1 overexpression treatment may provide a potential effective therapeutic option for MVO.

\section{Acknowledgements}

This work was supported by the National Natural Science Foundation of China (Grant No. 81770346).

\section{Disclosure Statement}

The authors declare no financial or other conflicts of interest.

\section{References}

1 American College of Emergency P, Society for Cardiovascular A, Interventions, O'Gara PT, Kushner FG, Ascheim DD, Casey DE, Jr., Chung MK, de Lemos JA, Ettinger SM, Fang JC, Fesmire FM, Franklin BA, Granger CB, Krumholz HM, Linderbaum JA, Morrow DA, Newby LK, Ornato JP, Ou N et al.: 2013 ACCF/AHA guideline for the management of ST-elevation myocardial infarction: a report of the American College of Cardiology Foundation/American Heart Association Task Force on Practice Guidelines. J Am Coll Cardiol 2013;61:e78140.

2 Menees DS, Peterson ED, Wang Y, Curtis JP, Messenger JC, Rumsfeld JS, Gurm HS: Door-to-balloon time and mortality among patients undergoing primary PCI. N Engl J Med 2013;369:901-909. 


\section{Cellular Physiology Cell Physiol Biochem 2018;49:2138-2150 \begin{tabular}{l|l|l} 
and Biochemistry 10.1159/000493817 & $\begin{array}{l}\text { @ } 2018 \text { The Author(s). Published by S. Karger AG, Basel } \\
\text { www.karger.com/cpb }\end{array}$ \\
\hline
\end{tabular}

- 3 de Waha S, Patel MR, Granger CB, Ohman EM, Maehara A, Eitel I, Ben-Yehuda O, Jenkins P, Thiele H, Stone GW: Relationship between microvascular obstruction and adverse events following primary percutaneous coronary intervention for ST-segment elevation myocardial infarction: an individual patient data pooled analysis from seven randomized trials. Eur Heart J 2017;38:3502-3510.

4 Kloner RA: The importance of no-reflow/microvascular obstruction in the STEMI patient. Eur Heart J 2017;38:3511-3513.

5 Bekkers SC, Yazdani SK, Virmani R, Waltenberger J: Microvascular obstruction: underlying pathophysiology and clinical diagnosis. J Am Coll Cardiol 2010;55:1649-1660.

-6 Rezkalla SH, Stankowski RV, Hanna J, Kloner RA: Management of No-Reflow Phenomenon in the Catheterization Laboratory. JACC Cardiovasc Interv 2017;10:215-223.

-7 Wang J, Chen H, Zhou Y, Su Q, Liu T, Wang XT, Li L: Atorvastatin Inhibits Myocardial Apoptosis in a Swine Model of Coronary Microembolization by Regulating PTEN/PI3K/Akt Signaling Pathway. Cell Physiol Biochem 2016;38:207-219. Kroemer G, Marino G, Levine B: Autophagy and the integrated stress response. Mol Cell 2010;40:280-293. Katheder NS, Khezri R, O'Farrell F, Schultz SW, Jain A, Rahman MM, Schink KO, Theodossiou TA, Johansen T, Juhasz G, Bilder D, Brech A, Stenmark H, Rusten TE: Microenvironmental autophagy promotes tumour growth. Nature 2017;541:417-420.

10 Sciarretta S, Maejima Y, Zablocki D, Sadoshima J: The Role of Autophagy in the Heart. Annu Rev Physiol 2017;10.1146/annurev-physiol-021317-121427.

11 Xie M, Kong Y, Tan W, May H, Battiprolu PK, Pedrozo Z, Wang ZV, Morales C, Luo X, Cho G, Jiang N, Jessen ME, Warner JJ, Lavandero S, Gillette TG, Turer AT, Hill JA: Histone deacetylase inhibition blunts ischemia/ reperfusion injury by inducing cardiomyocyte autophagy. Circulation 2014;129:1139-1151.

12 Bachmann M, Moroy T: The serine/threonine kinase Pim-1. Int J Biochem Cell Biol 2005;37:726-730.

13 Muraski JA, Rota M, Misao Y, Fransioli J, Cottage C, Gude N, Esposito G, Delucchi F, Arcarese M, Alvarez R, Siddiqi S, Emmanuel GN, Wu W, Fischer K, Martindale JJ, Glembotski CC, Leri A, Kajstura J, Magnuson N, Berns A et al.: Pim-1 regulates cardiomyocyte survival downstream of Akt. Nat Med 2007;13:1467-1475.

-14 Kulandavelu S, Karantalis V, Fritsch J, Hatzistergos KE, Loescher VY, McCall F, Wang B, Bagno L, Golpanian S, Wolf A, Grenet J, Williams A, Kupin A, Rosenfeld A, Mohsin S, Sussman MA, Morales A, Balkan W, Hare JM: Pim1 Kinase Overexpression Enhances ckit(+) Cardiac Stem Cell Cardiac Repair Following Myocardial Infarction in Swine. J Am Coll Cardiol 2016;68:2454-2464.

15 Wang X, Sun Y, Yang H, Lu Y, Li L: Oxidized Low-Density Lipoprotein Induces Apoptosis in Cultured Neonatal Rat Cardiomyocytes by Modulating the TLR4/NF-kappaB Pathway. Sci Rep 2016;6:27866.

16 Narendra D, Tanaka A, Suen DF, Youle RJ: Parkin is recruited selectively to impaired mitochondria and promotes their autophagy. J Cell Biol 2008;183:795-803.

17 Kubli DA, Gustafsson AB: Mitochondria and mitophagy: the yin and yang of cell death control. Circ Res 2012;111:1208-1221.

18 Kubli DA, Zhang X, Lee Y, Hanna RA, Quinsay MN, Nguyen CK, Jimenez R, Petrosyan S, Murphy AN, Gustafsson AB: Parkin protein deficiency exacerbates cardiac injury and reduces survival following myocardial infarction. J Biol Chem 2013;288:915-926.

-19 Wauer T, Simicek M, Schubert A, Komander D: Erratum: Mechanism of phospho-ubiquitin-induced PARKIN activation. Nature 2015;526:728.

20 Niccoli G, Burzotta F, Galiuto L, Crea F: Myocardial no-reflow in humans. J Am Coll Cardiol 2009;54:281292.

21 Wang XT, Wu XD, Lu YX, Sun YH, Zhu HH, Liang JB, He WK, Zeng ZY, Li L: Potential Involvement of MiR-30e$3 p$ in Myocardial Injury Induced by Coronary Microembolization via Autophagy Activation. Cell Physiol Biochem 2017;44:1995-2004.

22 Wang XT, Lu YX, Sun YH, He WK, Liang JB, Li L: TAK-242 Protects Against Apoptosis in Coronary Microembolization-Induced Myocardial Injury in Rats by Suppressing TLR4/NF-kappaB Signaling Pathway. Cell Physiol Biochem 2017;41:1675-1683.

23 Bravo-San Pedro JM, Kroemer G, Galluzzi L: Autophagy and Mitophagy in Cardiovascular Disease. Circ Res 2017;120:1812-1824.

-24 Przyklenk K, Dong Y, Undyala VV, Whittaker P: Autophagy as a therapeutic target for ischaemia / reperfusion injury? Concepts, controversies, and challenges. Cardiovasc Res 2012;94:197-205. 


\section{Cellular Physiology Cell Physiol Biochem 2018;49:2138-2150

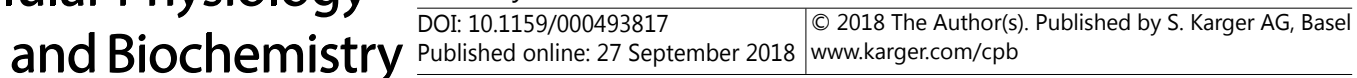 \\ Zhu et al.: Pim1 Prevents Cardiomyocytes Apoptosis via Upregulating Autophagy}

25 Matsui Y, Takagi H, Qu X, Abdellatif M, Sakoda H, Asano T, Levine B, Sadoshima J: Distinct roles of autophagy in the heart during ischemia and reperfusion: roles of AMP-activated protein kinase and Beclin 1 in mediating autophagy. Circ Res 2007;100:914-922.

26 Ma X, Liu H, Foyil SR, Godar RJ, Weinheimer CJ, Hill JA, Diwan A: Impaired autophagosome clearance contributes to cardiomyocyte death in ischemia/reperfusion injury. Circulation 2012;125:3170-3181.

27 Sala-Mercado JA, Wider J, Undyala VV, Jahania S, Yoo W, Mentzer RM, Jr., Gottlieb RA, Przyklenk K: Profound cardioprotection with chloramphenicol succinate in the swine model of myocardial ischemia-reperfusion injury. Circulation 2010;122:S179-184.

-28 Nakai A, Yamaguchi O, Takeda T, Higuchi Y, Hikoso S, Taniike M, Omiya S, Mizote I, Matsumura Y, Asahi M, Nishida K, Hori M, Mizushima N, Otsu K: The role of autophagy in cardiomyocytes in the basal state and in response to hemodynamic stress. Nat Med 2007;13:619-624.

29 Dutta D, Xu J, Kim JS, Dunn WA, Jr., Leeuwenburgh C: Upregulated autophagy protects cardiomyocytes from oxidative stress-induced toxicity. Autophagy 2013;9:328-344.

-30 Cottage CT, Neidig L, Sundararaman B, Din S, Joyo AY, Bailey B, Gude N, Hariharan N, Sussman MA: Increased mitotic rate coincident with transient telomere lengthening resulting from pim-1 overexpression in cardiac progenitor cells. Stem Cells 2012;30:2512-2522.

-31 Borillo GA, Mason M, Quijada P, Volkers M, Cottage C, McGregor M, Din S, Fischer K, Gude N, Avitabile D, Barlow S, Alvarez R, Truffa S, Whittaker R, Glassy MS, Gustafsson AB, Miyamoto S, Glembotski CC, Gottlieb RA, Brown JH, Sussman MA: Pim-1 kinase protects mitochondrial integrity in cardiomyocytes. Circ Res 2010;106:1265-1274.

32 Sussman MA: Mitochondrial integrity: preservation through Akt/Pim-1 kinase signaling in the cardiomyocyte. Expert Rev Cardiovasc Ther 2009;7:929-938.

-33 Bohensky J, Shapiro IM, Leshinsky S, Watanabe H, Srinivas V: PIM-2 is an independent regulator of chondrocyte survival and autophagy in the epiphyseal growth plate. J Cell Physiol 2007;213:246-251.

-34 Ai J, Li W, Zeng R, Xie Z, Liu H, Hou M, Tan G: Blockage of SSRP1/Ets-1/Pim-3 signalling enhances chemosensitivity of nasopharyngeal carcinoma to docetaxel in vitro. Biomed Pharmacother 2016;83:10221031.

-35 Gu H, Liu M, Ding C, Wang X, Wang R, Wu X, Fan R: Hypoxia-responsive miR-124 and miR-144 reduce hypoxia-induced autophagy and enhance radiosensitivity of prostate cancer cells via suppressing PIM1. Cancer Med 2016;5:1174-1182.

-36 Marino G, Niso-Santano M, Baehrecke EH, Kroemer G: Self-consumption: the interplay of autophagy and apoptosis. Nat Rev Mol Cell Biol 2014;15:81-94.

-37 Schiattarella GG, Hill JA: Therapeutic targeting of autophagy in cardiovascular disease. J Mol Cell Cardiol 2016;95:86-93.

-38 Xie H, Xu Q, Jia J, Ao G, Sun Y, Hu L, Alkayed NJ, Wang C, Cheng J: Hydrogen sulfide protects against myocardial ischemia and reperfusion injury by activating AMP-activated protein kinase to restore autophagic flux. Biochem Biophys Res Commun 2015;458:632-638.

-39 Liu L, Jin X, Hu CF, Li R, Zhou Z, Shen CX: Exosomes Derived from Mesenchymal Stem Cells Rescue Myocardial Ischaemia/Reperfusion Injury by Inducing Cardiomyocyte Autophagy Via AMPK and Akt Pathways. Cell Physiol Biochem 2017;43:52-68. 